\title{
Creativity characteristics in teaching students with learning disabilities among pre-service teacher in UPSI
}

\author{
Norfishah Mat Rabi*, Mohd Nasir Bin Masran \\ Universiti Pendidikan Sultan Idris, Malaysia, Tanjung Malim, Malaysia
}

\section{A R T I C L E IN F O}

Article history:

Received 7 September 2016

Received in revised form

28 October 2016

Accepted 9 November 2016

\section{Keywords:}

Characteristic

Creativity

Learning disabilities

Pre-service teacher

\begin{abstract}
A B S T R A C T
Due to developmental delay in cognitive, affective, psychomotor, language, and other aspect of difficulties, students with learning disabilities having a lot of problems in learning process. So, teaching student with learning disabilities is quite challenging for pre-service teachers. Thus, to understand better how creative are they when teaching students with learning disabilities, this study is carried out to identify to what extend pre-service teachers have the creativity characteristics based on Torrance creativity elements that include fluency, originality, flexibility and elaboration in teaching. A total of 24 respondents were selected purposively based on the pre-service teacher's placement in selected schools. A qualitative case-study was conducted and data was collected using recorded observation, interview and document analysis. The findings indicate that respondents with creativity characteristics are higher in the aspects of (1) fluency, (2) elaboration, (3) originality and (4) flexibility. For the frequency of creativity characteristics, it was found that respondents have the highest frequency characteristics in (1) fluency, followed by (2) originality, (3) flexibility and (4) elaboration. The implication of the study conducted is important for the nation development because creativity is among the human capital aspect that is important since the future economy depends on citizens with creative and innovative minds.
\end{abstract}

(C) 2016 The Authors. Published by IASE. This is an open access article under the CC BY-NC-ND license (http://creativecommons.org/licenses/by-nc-nd/4.0/)

\section{Introduction}

Creative thinking is an important survival skill for 21st century. We need this skill to help us face challenges in life, adapt and develop ourselves in education, business and life as a whole. Creative thinking which is related to flexibility and successful adaptation to everyday life is considered an entrepreneurship (Amabile, 1997). An individual who shows high creativity is more marketable and considered having special ability by employer. Therefore, many countries such as China, Hong Kong, Taiwan, Japan, Singapore and not forgetting Malaysia, have provided specific programmes in their education systems to increase creativity among students. Educationists are seen to intensify their teaching focus to creativity and innovation especially in the teaching of Science which is considered as the

\footnotetext{
* Corresponding Author.

Email Address: norfishah@fppm.upsi.edu.my (N. M. Rabi)

https://doi.org/10.21833/ijaas.2016.11.012

2313-626X/C 2016 The Authors. Published by IASE

This is an open access article under the CC BY-NC-ND license

(http://creativecommons.org/licenses/by-nc-nd/4.0/)
}

best medium to realize the effort (Kelly and Littman, 2000; Sternberg et al., 2005).

The insistence towards creativity is an issue in universal discussion in this world since creativity influence economic activities globally (Craft, 2006). School or higher institution of learning is the place to instill creativity for the future generation. Gustina and Sweet (2014) study proved that there are six reasons why creativity is important. Firstly, economy value, government's priority, education, reference, productivity, and administration. Torrance (1979) stated that if a country wants to change its education system to a creative one, the teachers have to be creative first. Therefore, human capital development for a country is through providing its students with knowledge and creativity in various fields of education (Lin, 2011; Shaheen, 2010).

Several researchers in creativity had summarized three main aspects about creativity in the classrooms. They are creative teaching (Gibson, 2010), teaching creativity (Jeffrey and Craft, 2004), and creative learning (Lucas, 2001). According to Craft (2006), teaching creatively means using imaginative approaches to make learning interesting and effective. Teachers play vital role in encouraging 
students' creative thinking through suitable approaches in the classroom (Kleiman, 2008; Livingston, 2010; Young, 2009). Teachers must not only know creative teaching approaches but also create creative learning environment. In fact Johansson (2004) also suggested that students should be encouraged to collaborate with other students in their learning activities so that they can be more creative.

To be a creative teacher, creativity must be inculcated. This is explained by Sternberg (2006) that educational programme should not only focus at enhancing creativity but also focusing at students' existing potential creativity. A creative teacher will transform past ideas for improvisation and produce a more attractive new product (Starko, 2014). If a lecturer wants to encourage creativity and to show creativity intelligence among students, the creative thinking aspect should be included in assignments and tests (Sternberg, 2006). Study by Scott et al. (2004) has proven that divergent thinking, problem solving, and creative attitude are most effective creative exercise. According to Scott et al. (2004), creativity can be trained. Creativity training programme can be conducted based on idea generating exercise, imaginative exercise and cognitive exercise and thinking skills exercise.

How a creative person does looks like? According to Starko (2014), creativity is seen in a creative individual and products that show creative characteristics. In this case, firstly, creativity involves new product (idea, arts products, innovation and others). To be creative, the idea and product must be something new. Secondly, creativity should include suitability of resource or idea that can be referred to in the cultural context. The concept of creativity differs among culture (Kaufman and Sternberg, 2006; Lubart, 2010). It involves individual, spiritual values or a Nation's development. Therefore, teachers need to see students' background when producing creativity taking into accounts various social aspects and cultural value. A creative person has metaphorical thinking, problem solving skill, able to self-evaluate and self-assess, logical thinking, and high rate of visualization (Starko, 2014; Ward and Kolomyts, 2010). They can generate ideas, make inference, relate, predict, make hypothesis and analogy, and synthesize. For problem solving, the creative process involves activities such as recognizing problem, interpret problem, application of existing knowledge to handle problems until problems are solved. So creativity is a mental activity to produce new, extraordinary and unique ideas (Beghetto and Kaufman, 2010). Some creative abilities can be learned by building new knowledge based on old ideas (Runko, 2007). Some of the techniques use to encourage creativity is idea generation and divergent thinking (Sternberg, 2006). Divergent thinking comprises fluency (ability to generate many ideas), flexibility (ability to generate many types of ideas or ideas from many different perspectives) and elaboration (ability to add information to improve ideas) (Ward and Kolomyts, 2010).

Westby and Dawson (1995) found that creative persons are impulsive, emotional, and opportunists; whereas, less creative persons are very dependable, appreciative and good natured. But creativity can be influenced by activities carried out. Gardner (2006) stated that five activities that requires creative individual to do are problem solving, produce concept or theory, create product, achievement style, and show great and unique achievement. To stimulate creativity, a teacher must encourage students to think laterally and associate different ideas. Lateral thinking is one way of solving problems by using imaginative ideas and not by logical or traditional thinking (De Bono, 1992). It is a thinking that emphasizes multiple answers and can be used to get away from old ideas that have been practiced before. They must be able to translate and use learning in new context, look at things from various perspectives and test with different approaches in problem solving. For product creation, unique and original idea is produced from creative thinking process that involves old ideas for improvisation and making new attractive (Starko, 2014). According to Wright (2010), creative process involves seven steps that are, findings and problem solving, flexibility, fluency, elaboration, transformation, objectivity and selectivity and aesthetic appreciation.

Basically, creativity models can be used to explain creativity process that aim to identify and measure components to produce creativity. Studies on creativity can be conducted based on several creativity models (Lubart, 2001; Scott et al., 2004). Torrance Framework for Creative Thinking (TFCT) (Torrance, 1979) is one of the creativity tests based on fluency, flexibility, originality and elaboration (Kim, 2006; Torrance, 1979). With reference to the test, researchers in creativity field have divided the creativity characteristics into several components such as original ideas, frequency of relevant ideas (fluency), categorical ideas (flexibility), elaboration of ideas (elaboration) and others (Scott et al., 2004; Torrance, 1979). In fact, most researchers evaluate creative process based on fluency, flexibility, originality, and elaboration (Tsai, 2014; Plucker and Renzulli, 1999; Sternberg and O'Hara, 1999; Vincent et al., 2002). A cognitive style of divergent or associational thinking (Mednick, 1962) is sometimes called originality (Eysenck, 1993). The responses are subsequently scored on objective scales measuring assumingly different dimensions of creative ability, traditionally fluency (number of responses), flexibility (number of different categories covered by the responses), originality (statistical infrequency of the responses) and elaboration (amount of details given).

Creativity is always being referred to the humanistic theory. The humanistic theory pushes what we need to be encouraged to advance creatively, regardless of the challenges. It is not the suppression of creativity that makes us creative but 
the encouragement that makes us creative. The major tenet of humanistic theory is that humans have six basic needs. These needs need to be met before we can thrive. Once these needs are met we can reach self-actualization and are now free and comfortable enough to express ourselves in a creative manner. This theory argues that environment is not a factor in creativity because if the person is able to meet the six basic needs they can then tend are creative.

Convergent and Divergent Thinking (CDT) is a theory about the way some people view a problem and come up with a solution. Ideas of CDT are supported by Sternberg (2006). Convergent thinkers tend to concentrate their thoughts down the path of a single solution. Divergent thinkers on the other hand bring forth multiple solutions to each project. At the beginning of the creative process, divergent thinking generally occurs. We could generate many different possible solutions to the problem through brainstorming, creating art works, free writing, or mind mapping. By using both forms of thinking together we come up with as many solutions as possible to the problem at hand then narrow it back down to the solution we will use for our project. These two forms of thinking should be used together at the same time, rather in different stages of development. The relationship of individual differences in creativity to individual differences in cognitive abilities, such as intelligence, is still discussed. Indeed, any possible relationship between creativity and intelligence has been proposed (Sternberg and O'Hara, 1999). In one extreme version, creativity and intelligence are regarded as totally independent, a position especially taken by some cognitive psychologists with strong focus on the creative process (Weisberg, 1999). These authors see creativity as a mental operation accessible to everyone, only dependent on domainspecific knowledge (i.e. the amount of exposure to and expertise in a given field) and deliberate practice. Their position therefore denies not only the influence of intelligence, but of any individual difference beyond knowledge and motivational factors, on creativity; according to Starko (2014), creativity influenced by cognitive, affective, motivational and social environment aspects. The creativity element in cognitive aspect involves general or specific knowledge, perception, originality, complex view such as analysis, integration and using different idea or concept, open mindedness, and creativity awareness (Beghetto and Kaufman, 2010).

Preparation to be a teacher involves a lot of process. Apart from receiving knowledge theoretically, one has to attend practical training as a pre-service teachers' in school. In order to enhance the teaching profession, pre-service teachers' should equip themselves with knowledge and teaching skills before they are offered to be qualified and quality teachers. In teaching students with special needs, creativity needs to be given attention by pre-service teachers' because teaching students with special needs differs from teaching the normal students. As pre-service teachers, the training duration is the best time for them to develop creativity, apply the characteristics of creativity that they possess, produce creative products, and create creative teaching and learning environment. Apart from having the opportunity to use teaching skills, preservice teacher can sharpen their creative abilities that they may not have the opportunity to show. Nevertheless, does the learning process in the university be to produce creative and innovative teachers? To what extent pre-service teachers' undergoing teacher training in the university has creative skills to teach students in school? Hence, to understanding the creativity of pre-service teacher in teaching practicum in schools, four objectives and four research questions have been designed to carry out the study due to fluency, originality, flexibility, and elaboration in teaching.

\section{Research methods}

This study was conducted for duration of 12 months. This qualitative case study uses observation, interview and document analysis for data collection. For observation, the instrument used was video recording, and observation notes, interview questions, and analyzing teaching aids used during teaching. Data is collected during teaching and learning session comprising set induction teaching steps and conclusion. Every activity conducted is observed and information is jotted down based on the creativity characteristics comprising four creativity elements that is, fluency, originality, flexibility and elaboration. The respondents are Semester 7 students undergoing teaching practicum for a period of 16 weeks in selected schools. A total of 24 respondents were selected using purposive sampling based on the pre-service teachers' allocation in schools under Special Education Integration Programme. The respondents selected in this study were from eight schools. The subjects taught by the respondents were Malay language, Mathematics, Living Skills (Cookery, Sewing and Agriculture), Arts Education, Islamic Education, and Science. From the total 24 samples, the Subjects teaching Malay language is $20.83 \%$, Science $8.33 \%$, Mathematics $16.67 \%$, Arts Education 8.33\%, Living Skill Sewing 12.50\%, Living Skills Cookery 16.67\%, Living Skills Agriculture 8.33\%, and Islamic Education $8.33 \%$.

\section{Analysis results}

Creativity cannot be seen with the naked eye but can be evaluated by observing an individual. This is explained by Starko (2014) that creativity is seen in creative individual and materials that have creative characteristics. In this context, firstly, creativity involves new product (idea, arts product, innovation and others). To be creative, the idea and product must be new and can be tested (Sternberg, 1999). Clearly, creativity is related to the ability to produce 
new product or idea (Lubart, 2010; Sternberg and Lubart, 1995). This study adapts Torrance Framework for Creative Thinking creativity characteristics that contains Fluency, originality, flexibility and elaboration characteristic (Kim, 2006; Torrance, 1979). Based on observation, interview and official document analysis, the finding shows that the respondents show different characteristics of creativity and the findings is reported based on three research questions.

\subsection{Fluency}

Creativity characteristics in fluency refer to the competency in producing idea to solve problems, increase understanding and remember information. Data is collected by observation and video recording. The research findings show that three respondents can produce ideas to solve problem in teaching spontaneously, 17 respondents have creativity characteristics in fluency able to produce ideas to increase students' understanding and 19 respondents had successfully produce ideas to remember information. Overall score found that the respondent's frequency in producing ideas to solve problems was 3 times, frequency in producing ideas to increase understanding was 19 times and frequency in producing ideas to remember ideas was 44 times (Table 1).

Table 1: Creativity characteristics in fluency

\begin{tabular}{|c|c|c|c|}
\hline Number & \multicolumn{1}{c}{$\begin{array}{c}\text { Fluency } \\
\text { characteristics }\end{array}$} & $\begin{array}{c}\text { Observation } \\
(\%)\end{array}$ & $\begin{array}{c}\text { Interview } \\
(\%)\end{array}$ \\
\hline 1 & Problem solving & 7.69 & 4.55 \\
\hline 2 & $\begin{array}{c}\text { Remember } \\
\text { information }\end{array}$ & 43.59 & 28.79 \\
\cline { 2 - 4 } 3 & $\begin{array}{c}\text { Understand } \\
\text { information }\end{array}$ & 48.72 & 66.67 \\
\cline { 2 - 4 } & Total & 100 & 100 \\
\hline
\end{tabular}

The finding shows that $7.69 \%$ respondents are creative in solving students' problem, $43.59 \%$ can produce creative ideas to assist students to remember previous lessons and $48.72 \%$ had successfully produce ideas to understand information delivered. Whereas for frequency, the interview data shows that $4.55 \%$ respondents use creativity to solve problems, respondents frequency to use creativity in producing ideas to assist students understand the subject content is $28.79 \%$ and respondents frequency using creativity to assist students to remember information and subject content learned is $66.67 \%$.

\subsection{Originality}

The second creativity characteristic is originality. It refers to unique and outstanding original ideas. The information is synthesized in a new form. The finding shows that eight respondents were able to generate unique ideas and four respondents were able to generate original ideas. Frequency score shows that ability to generate unique ideas is 22 times and ability to produce original idea is 5 times (Table 2).

Table 2: Creativity characteristic in originality

\begin{tabular}{|cc|c|c|}
\hline Number & Originality & $\begin{array}{c}\text { Observation } \\
(\%)\end{array}$ & $\begin{array}{c}\text { Interview } \\
(\%)\end{array}$ \\
\cline { 2 - 4 } 1 & Unique idea & 66.67 & 81.48 \\
\cline { 2 - 4 } 2 & Original idea & 33.33 & 18.52 \\
\cline { 2 - 4 } & Total & 100 & 100 \\
\hline
\end{tabular}

For originality characteristic, observation and analyzing video recording shows that $66.67 \%$ respondents could generate unique idea and $33.33 \%$ could generate original ideas. For original frequency characteristic, data analysis for interview shows that respondent's frequency in generating unique ideas in teaching is $81.48 \%$ and respondent's frequency to produce original ideas is $18.52 \%$.

\subsection{Flexibility}

The third creativity is flexibility that relates to production of various ideas in thinking that involves the ability to innovate creativity from multiple aspects. It was found that seven respondents shows that the flexibility characteristic in this study is 8 times for teaching strategy, 2 times for different views and once for flexibility in innovating ideas (Table 3).

Table 3: Creativity Characteristic in Flexibility

\begin{tabular}{|c|c|c|c|}
\hline Number & Flexibility & $\begin{array}{c}\text { Observation } \\
(\%)\end{array}$ & $\begin{array}{c}\text { Interview } \\
(\%)\end{array}$ \\
\hline 1 & $\begin{array}{l}\text { Different } \\
\text { strategy }\end{array}$ & 66.67 & 72.73 \\
\hline 2 & Different view & 22.22 & 18.18 \\
\hline 3 & Innovation & 11.11 & 9.09 \\
\hline & Total & 100 & 100 \\
\hline
\end{tabular}

For flexibility characteristic, the respondents had creativity in producing various ideas in thinking that involves the ability to innovate creativity from various views, approaches and strategies. Data analysis shows that $66.67 \%$ respondents are creative in using different strategies in teaching, $22.22 \%$ respondents are creative in using different approaches, and $11.11 \%$ are creative in innovating teaching techniques. For flexibility characteristics, the respondent's frequency in using different strategies in teaching is $72.73 \%$, the respondent's frequency to generate different view is $18.18 \%$ and frequency in innovating teaching is $9.09 \%$.

\subsection{Elaboration}

The fourth creativity characteristic is elaboration. It refers to the process of idea development through detail elaboration that will increase interest and understanding in learning a topic. This is related to the ability to develop ideas and make them more interesting. The finding shows that 17 respondents have creativity that can develop ideas through detail explanation to enhance students' interest and understanding. Overall, the respondent's frequency 
Table 4: Creativity characteristic in elaboration

\begin{tabular}{ccc|c|} 
Number & Elaboration & Observation (\%) & Interview (\%) \\
\cline { 2 - 4 } 1 & Detail explanation to arouse interest & 41.18 & 43.48 \\
\hline 2 & Detail explanation for understanding & 58.82 & 56.52 \\
\cline { 2 - 4 } & Total & 100 & 100 \\
\hline
\end{tabular}

Observation finding shows that respondent's creativity in elaboration involves development of ideas in activity through detail explanation that can increase interest and understanding in learning a topic. It was found that $41.18 \%$ use creativity to give detail explanation to attract students' interest and $58.82 \%$ used creativity to give detail explanation for students to understand subject content. For frequency of elaboration $43.48 \%$ respondents give detail explanation to attract students' interest and $56.52 \%$ respondents give detail explanation to enable students to understand teaching.

Overall, the findings show that the number of creative respondents is higher in fluency $(50.65 \%)$, second, is elaboration $(22.08 \%)$, third is originality $(15.58 \%)$ and fourth is flexibility (11.69\%). For frequency of Creativity characteristic, it was found that $44.00 \%$ respondents have frequency in fluency in teaching, $18.00 \%$ have $7.33 \%$ frequency in originality and $30.67 \%$ have frequency in elaboration.

\section{Discussion}

A creative individual always strive to solve various problems or able to produce something new and useful in specific areas from time to time (Ainon, 2008). This study has proven that most UPSI's preservice teachers have fluency in producing ideas to solve problems, increase understanding and remember information learned. The finding is supported by study conducted by Westby dan Dawson (1995) that state a creative individual has metaphorical thinking, has skills in problem solving, self-evaluate and self-assess, logical thinking, and has high visualization rate. According to the study by Tsai (2014), fluency, flexibility and originality is more accurate in evaluating creativity achievement. Ideas that have the tendency to be similar can be combined and integrated in new presentation in order to understand a matter more clearly. Fluency is the ability to think about various ideas spontaneously. Fluency IA also seen from the context of delivering systematic information with language that is easily understood. To deliver ideas fluently one needs creativity. In fact Gardner (1993) stated that a creative individual will, from time to time, tries to solve problems, or strive to produce something new and useful in specific areas. Fluency in delivering ideas prove a person's creativity and this can be identified based on several characteristics such as fluency in comparing, changing, counting, giving definition, explaining, labeling, identifying, listing, matching, naming, designing, paraphrasing, predicting and summarizing. Torrance and Ball (1984) and Torrance (1979) has proven that the more ideas given by an individual, the higher his or her competency and fluency. An idea is the result of creative thinking that is important to assist an individual to make decision, solve problem and generating abstract and concrete ideas (Yew et al., 2011). In fact, Sternberg (1999) stated that learning based on problem solving is one of the activities that can stimulate creativity. In problem solving activity, information and ideas are collected, arranged and analyzed to get the solution for the problem.

The second creativity characteristic that is most prominent among pre-service teachers is elaboration. This finding is supported by Ward and Kolomyts (2010) that by mastering elaboration characteristic a person is able to add information and improve ideas. Elaboration is a process of developing ideas by detail explanation that can increase interest and understanding in learning a certain topic. This is related to ability in developing ideas and adding ideas to be more interesting. In this study, the elaboration elements comprise assessment, critics, setting, evaluation, grading, judgment, measurement, selection and test. Apart from the potential to stimulate active learning, creativity is also able to assist students to elaborate concepts or ideas and attract students, and thus produce meaningful learning (Elliot et al., 2000).

For originality characteristics, the finding shows that only one third of the respondents demonstrate creativity in producing original, unique or outstanding ideas; this involves thinking ability that can produce new, unique and interesting ideas. This is confirm by Starko (2014) that an individual who always give original ideas normally able to give creative ideas. Creativity in teaching means teacher using imaginative approaches to make learning more interesting, effective, fun and liked by students. This is related to ability to create and produce or in new form through imagination skill (Craft, 2006; Gustina and Sweet, 2014). However, new finding shows that teacher trainees lack unique and original ideas to generate new ideas; whereas creativity is thinking process that helps to assist a person in producing new ideas. Pre-service teachers also lack ability in synthesizing. Synthesizing skills combine ideas, elements, items and separate matters to produce a comprehensive picture in the form of statements, essay, arts and artifacts. This finding is supported by Westby and Dawson (1995) study that proved creativity can be seen in ability to synthesize ideas. This skill is used when a person wants to find new ideas or alternatives. In fact Ainon and Abdullah (2005) stated that by having in depth knowledge in a 
certain field, a person can produce original and useful. Knowledge and useful ideas encourage creativity in producing types of ideas that is outside the norms of a particular field Creativity is a mental activity to produce new, outstanding and unique ideas (Beghetto and Kaufman, 2010).

Characteristic of creativity that is the least mastered by pre-service teachers is flexibility. This characteristic is related to the ability to produce multiple ideas in thinking. It involves the ability to adapt creativity by looking at things from various perspectives and different strategies and approaches. According to Jeffrey and Craft (2004), teaching creatively means using imaginative approaches to make learning more interesting and effective. In the flexibility context, a creative individual can change ideas, instruct, differentiate, use, interject, translate and predict. As creativity is a mental activity to produce new, unique and outstanding ideas (Beghetto and Kaufman, 2010), the production of new and unique ideas is related to cognitive and non-cognitive skills. This shows flexibility is able to produce a certain idea or different answer and look at problems creatively as a new assignment. A creative individual has flexibility characteristic that can face whatever changes and challenges. However, if an individual lacks of creativity, flexibility does not exist in that person. Therefore to get in-depth knowledge, a person needs to mingle with people with different knowledge (Johansson, 2004). By this way, they can generate ides, different views and thinking that can generate creativity.

\section{Conclusions}

A creative individual will think of various perspectives that have the possibility to solve problems. He/she has the ability to think from different perspectives. They also have the in-born ability to change existing methodology or approaches. Usually a creative individual can generate outstanding or unique ideas. Creativity also encourages individuals to have interests in multiple areas and enjoy life from various perspectives. The characteristics needed for creativity are ready to be independent in thinking, does not give easily give up, able to communicate well, more interested in concept, inclination to learn various knowledge, humorous, accept new ideas and clear objective in life (Sternberg, 1999). Many creative individuals have side characteristics that make them difficult to mix around with other people and have disorder life. Therefore, a creative individual will look strange, not bothered about other people, proud and less sociable.

\section{Acknowledgment}

The authors would like to express utmost appreciations to the Research Management and Innovation Center (RMIC) for the allocation of the Research Grant University.

\section{References}

Abdullah $\mathrm{H}$ and Ainon $M$ (2005). Motivating creativity in children. PTS Publications, Selangor, Malaysia.

Ainon M (2008). Psychology in Successful Person: Knowing the characteristics and thinking style of successful person. PTS Professional Publishing, Kuala Lumpur, Malaysia.

Amabile TM (1997). Entrepreneurial creativity through motivational synergy. The Journal of Creative Behavior, 31(1): 18-26.

Beghetto RA and Kaufman JC (2010). Cultivating creativity in the classroom. Cambridge University Press, UK: 447-463.

Craft A (2006). Creativity in schools' education. In: Jackson N, Oliver M, Shaw M and Wisdom J (Eds.), Developing Creativity in Higher Education. Routledge, Abingdon, UK.

De Bono E (1992). Serious Creativity. Harper Collins, London, UK.

Elliott SN, Kratochwill TR, Cook JL and Travers JF (2000). Educational psychology: Effective teaching, effective learning. $3^{\text {rd }}$ Edition, McGrawHill Companies, Boston, USA.

Eysenck HJ (1993). Creativity and personality: Suggestions for a theory. Psychological Inquiry, 4(3): 147-178.

Gardner H (1993). Creating minds. Basic Books, New York, USA.

Gardner H (2006). Five minds for the future. Harvard Business School Press, Boston, USA.

Gibson R (2010). The 'art' of creative teaching: implications for higher education. Teaching in Higher Education, 15(5): 607-613.

Gustina C and Sweet R (2014). Creatives Teaching Creativity. International Journal of Art and Design Education, 33(1): 46-54.

Jeffrey B and Craft A (2004). Teaching creatively and teaching for creativity: distinctions and relationships. Educational Studies, 30(1): 77-87.

Johansson F (2004). The Medici effect: Breakthrough insights at the intersection of ideas, concepts, and cultures. Harvard Business Press, Boston, USA.

Kelly T and Littman J (2001). The art of innovation. Broadway Business, New York, USA.

Kim KH (2006). Can we trust creativity tests? A review of the Torrance tests of creative thinking (TTCT). Creativity Research Journal, 18(1): 3-14.

Kleiman P (2008). Towards transformation: conceptions of creativity in higher education. Innovations in Education and Teaching International, 45(3): 209-217. 
Lin YS (2011). Fostering creativity through education-a conceptual framework of creative pedagogy. Creative Education, 2(3): 149-155.

Livingston L (2010). Teaching creativity in higher education. Arts Education Policy Review, 111(2): 59-62.

Lubart T (2010). Cross-cultural perspectives on creativity. In: Kaufman JC and Sternberg RJ (Eds.), Cambridge handbook of creativity. Cambridge University Press, New York, USA: 265-278.

Lucas B (2001). Creative teaching, teaching creativity and creative learning. In: Craft A, Jeffrey B and Leibling $M$ (Eds.), Creativity in education. Continuum, New York, USA: 35-44

Mednick S (1962). The associative basis of the creative process. Psychological Review, 69(3): 220-232.

Plucker JA and Renzulli JS (1999). Psychometric approaches to the study of human creativity. In: Sternberg RJ (Eds.), Handbook of creativity, Cambridge University Press, Cambridge, England: 35-61.

Runco, M.A., 2007. Creativity Theories and Themes: Research, Development and Practice. Academic Press, Amsterdam, Netherlands.

Scott G, Leritz LE and Mumford MD (2004). The effectiveness of creativity training: A quantitative review. Creativity Research Journal, 16(4): 361388.

Shaheen R (2010). Creativity and education. Creative Education, 1(3): 166-169.

Starko AJ (2013). Creativity in the classroom: Schools of curious delight. $5^{\text {th }}$ Edition, Routledge, New York, USA.

Sternberg RJ (1999). Handbook of creativity. Cambridge University Press, Cambridge, UK.

Sternberg RJ (2006). The nature of creativity. Creativity Research Journal, 18(1): 87-98.

Sternberg RJ and Lubart TI (1995). Defying the crowd: Cultivating creativity in a culture of conformity. Free Press, New York, USA.
Sternberg RJ and O'HARA LA (1999). 13 Creativity and Intelligence. In: Sternberg RJ (Eds.), Handbook of creativity. Cambridge University Press, Cambridge, UK: 251-272

Sternberg RJ, Lubart TI, Kauffman JC, and Pretz JE (2005). Creativity. In: Holyoak KJ and Morrison RG (Eds.), The Cambridge handbook of thinking and reasoning: 351-369. Cambridge University Press, Cambridge, UK.

Torrance EP (1979). The search for satori and creativity. Bearly Limited, Buffalo, New York, USA.

Torrance EP and Ball OE (1984). The Torrance tests of creative thinking streamlined (revised) manual, figural $\mathrm{A}$ and $\mathrm{B}$. Scholastic Testing Service. Inc, Bensenville, USA.

Tsai KC (2013). A review of the Effectiveness of Creative Training on Adult Learners. Journal of Social Science Studies, 1(1): 17-30.

Vincent AS, Decker BP and Mumford MD (2002). Divergent thinking, intelligence, and expertise: A test of alternative models. Creativity Research Journal, 14(2): 163-178.

Ward TB and Kolomyts Y (2010). Cognition and creativity. In: Kaufman JC and Sternberg RJ (Eds.), The Cambridge handbook of creativity. Cambridge University Press, Cambridge, UK: 93112.

Weisberg RW (1999). Creativity and knowledge: A challenge to theories. In: Sternberg RJ (Eds.), Handbook of creativity: 226-251. Cambridge University Press, Cambridge, UK.

Westby EL and Dawson VL (1995). Creativity: Asset or burden in the classroom?. Creativity Research Journal, 8(1): 1-10.

Wright S (2010). Understanding crativity in early chilhood. Sage, Los Angeles, USA.

Yew KK (2011). You Are Creative: Let Your Creative Bloom. Puchong, Anvantage Quest Publication, Selangor, Malaysia.

Young LP (2009). Imagine creating rubrics that develop creativity. The English Journal, 99(2): 7479. 